\title{
Social Capital, Gender and Educational Level - Impact on Self-Rated Health
}

\author{
Malin Eriksson*, Lars Dahlgren, Urban Janlert, Lars Weinehall and Maria Emmelin \\ Epidemiology and Global Health, Department of Public Health and Clinical Medicine, Umeå University, SE-901 85 \\ Umeå, Sweden
}

\begin{abstract}
Objectives: Social capital has been recognized as one important social determinant for health, but we still have limited knowledge about how it can be used to explain inequality in health. This study investigated the links between individual social capital and self-rated health by gender and educational level, and analyzed if access to social capital might explain the observed disparities in self-rated health between men and women and different educational groups. Study design: A cross-sectional survey in Northern Sweden. Methods: A social capital questionnaire was constructed and mailed to 15000 randomly selected individuals. Different forms of structural and cognitive social capital were measured. Self-rated health was used as the outcome measure. Crude and adjusted OR and 95\% CI were calculated for good selfrated health and access to each form of social capital. Multivariate regression was used to analyze how sociodemographic factors and access to social capital might influence differences in self-rated health by gender and educational level. Results: Access to almost each form of social capital significantly increased the odds for good self-rated health for all groups. A higher education significantly increased the odds for access to each form of social capital, and being a man significantly increased the odds for having access to some forms of social capital. The health advantage for higher educated and men partly decreased when controlling for access to social capital. Conclusions: Access to social capital can partly explain the observed health inequality between men and women and different educational groups. Strengthening social capital might be one way of tackling health inequality. It is important to consider the structural conditions that create unequal opportunities for different groups to access social capital.
\end{abstract}

Keywords: Social capital, gender, educational level, self-rated health, health inequality.

\section{INTRODUCTION}

Social capital has become a vital but debated concept within social epidemiology and public health research. Whether social capital is a collective feature, "social networks, the reciprocity that arise from them, and the value of these for achieving mutual goals" [1 p.1], or an individual attribute, "the ability of actors to secure benefits by virtues of memberships in networks and other social structures [2 $\mathrm{p}$. 6 ], has been widely discussed. Currently several researchers advocate that social capital has both individual and collective characteristics $[3,4]$ even though the level of analysis, i.e., individual or collective, requires distinct theoretical and methodological considerations.

Collective, i.e., social cohesion, approaches [5-8] view social capital as something characterizing whole communities or states by levels of social participation, trust, and reciprocity. Collective social capital is believed to promote various collective and individual benefits such as democracy, economic sustainability as well as health $[5,6]$. Since social capital is viewed as a collective and non-exclusive good [4], it is hypothesized that individuals who live in high social capital areas may benefit despite being low-trusting or low participating individuals.

*Address correspondence to this author at the Epidemiology and Public Health Sciences, Department of Public Health and Clinical Medicine, Umeå University, SE-901 85 Umeå, Sweden; Tel: +46 (0) 90785 3346, +46 7681 22 331; Fax: +46 (0) 9013 8977;

E-mail:malin.eriksson@socw.umu.se
The current paper relies on an individual, i.e., social network, approach towards social capital. Social capital is viewed as resources accessible to individuals by involvement in social networks or other social structures $[9,10]$. These can be various forms of support, information, knowledge, or material resources that are useful for reaching certain ends (such as health) that would not be possible to reach in the absence of the networks. These resources do not reside within the individual (i.e., intrapersonal resources) but in the structure of his/her social networks. Thus, to gain access to social capital an individual must be related to others. Access to individual social capital is believed to influence health by ensuring social support, control, status and participation that may decrease levels of stress and thereby have positive effects on health [11].

\section{Social Capital and Health}

Numerous studies have investigated the potential link between social capital and health outcomes such as mortality [12-14], cardiovascular diseases [15] obesity, physical inactivity [16] and self-rated health [17-22]. To date, the strongest association has been found between trust (as an indicator of social capital) and self-rated health [23]. Selfrated health is a subjective summary of how people perceive their overall health [24] and has shown high reliability in repeated measurements [25]. Self-rated health has an independent effect as a predictor of mortality $[26,27]$ and strengthens the effect of biomedical risk factors in predicting stroke, especially among men [28]. 
The link between social capital and health is still somewhat unclear. Studies have been inconclusive or shown conflicting results. Consequently, the field has been criticized as being based on weak evidence and limited theoretical conceptualization [29, 30]. However, others interpret the discrepancy in research results as partly due to "lack of convergence in the social capital measures used... and the extent to which residual confounding is handled" [22 p. 2271]. Many studies depend on secondary data retrieved from existing registers or surveys and this result in the use of single indicators to measure social capital. Harpham, Grant and Thomas [31] underline the need of specifically designed questions for the explicit purpose of measuring social capital in various contexts. Distinguishing between structural and cognitive social capital has also been identified as important for deriving more conclusive results about the relation between social capital and health [3].

A systematic review of 1996-2006 literature on the link between social capital and physical health showed that of the 51 reviewed studies, 43 were based on a social cohesion approach (ecological or multilevel) while only 8 applied an individual level approach [23]. Even if the link between collective social capital and health needs to be expanded, development of the relation between individual social capital and health is essential since it can contribute to an increased understanding of the observed health inequality between groups within a community. The underlying assumption is that social and gender inequalities in health can be at least partly understood by the degree of social capital that is accessible to different groups in society. Access to social capital is in turn influenced by social structural conditions and therefore not equally distributed in society [32].

Rose [18] explored the role of social and human capital in explaining inequalities in health among Russians. The results indicate that both human and social capital account for much of the variation in self-rated physical and emotional health. Social capital indicators such as participation in or exclusion from various networks, reliable friends, control over life, as well as trust, increase levels of good health more than human capital (i.e., education, age, gender, household income and socioeconomic status). In Finland, Hyyppä and Mäki [19] examined access to social capital among the Swedish-speaking minority and the Finnishspeaking majority living in the same community. They concluded that the Swedish-speaking group had access to more social capital (civic trust, civic participation) and that membership in religious associations and number of helpful friends was positively associated with self-rated health; mistrust had a negative association.

The annual Swedish national public health survey, conducted by the Swedish National Institute of Public Health, demonstrates clear social and gender inequalities in health. Women have higher levels of illness absence and higher levels of health care utilization than men [33]. Also, a higher proportion of the Swedish women than men have poor selfrated general and mental health [34]. More Swedes with high education (i.e., university) rate their health as good compared to those with less education (basic and secondary) [34]. Those with high education are also less likely to be obese or smoke compared with people with low education [35].
Investigating the association between self-rated health and access to different forms of social capital may increase understanding of observed gender and social inequality and how to intervene against this inequality within a Swedish context.

\section{Aim}

The overall aim of this study was to investigate the links between individual social capital and self-rated health by gender and educational level.

The specific aims were:

- To describe the distribution of self-rated health by sociodemographic factors and access to social capital

- To determine the association between structural and cognitive social capital and self-rated health

- To assess differences in access to structural and cognitive social capital

- To analyze how access to structural and cognitive social capital might influence differences in self-rated health

\section{Different Forms of Social Capital}

The theoretical development of social capital has led to a distinction between different forms of capital. Most current definitions distinguish between structural and cognitive social capital [22, 31]. Structural social capital concerns connections and participation in various network activities [31, 36] while cognitive social capital refers to less tangible factors such as perceptions of trust, solidarity, and reciprocity [36].

The structural components of social capital can in turn be divided into bonding, bridging, and linking social capital. Bonding social capital is characterized by involvement in (often small) networks with strong ties between the members that strengthen common identities and function as a source of help and support among members. Bridging social capital is described as involvement in networks with weaker ties that link people from different networks together and thereby become important sources of information and resources [6, 37]. Szreter and Woolcock [7] introduced the concept of linking social capital which consists of involvement in networks with vertical ties between people in different formal or institutionalized power hierarchies in a society. Table $\mathbf{1}$ illustrates the distinction between structural and cognitive social capital and their corresponding components.

Different forms of social capital are believed to affect health in various ways. Harpham et al. [31] state that structural social capital can influence the access to institutions and resources which might provide support and reduce the effect of negative life events. Thus, bonding social capital might provide emotional support that thereby reduces stress [38]. Bridging and linking social capital are believed to increase access to health information, health services and other resources that might improve the ability to solve health problems [38]. Access to cognitive social capital can influence health by enhancing feelings of safety and self esteem [38]. Many studies indicate a stronger association between self-rated health and the cognitive forms of social capital than with the structural components $[23,39,40]$. 
Table 1. Structural and Cognitive Social Capital - Definitions and Components

\begin{tabular}{|ll|l|}
\hline \multicolumn{2}{|c|}{$\begin{array}{c}\text { STRUCTURAL SOCIAL CAPITAL } \\
\text { Participation in Social Networks }\end{array}$} & \multicolumn{1}{c|}{$\begin{array}{c}\text { COGNITIVE SOCIAL CAPITAL } \\
\text { Perceptions of Trust, } \text { Reciprocity and Safety }\end{array}$} \\
\hline \hline$\bullet \quad$ Involvement in Bonding Networks & $\bullet$ & Trust; generalized, personalized and institutionalized \\
Involvement in Bridging Networks & Reciprocity norms \\
Involvement in Linking Networks & Safety \\
\hline
\end{tabular}

\section{MATERIALS AND METHODS}

\section{Study Design and Data Collection}

This study used survey data from a random sample of people living in region of Umeå, Northern Sweden. A social questionnaire was mailed to 15000 randomly selected individuals, 18-84 years old, and stratified by municipality. Data collection was performed in collaboration with Statistics Sweden during October 2006 - January 2007. Data from a total of 4836 women and 3980 men $(n=8816)$ were collected.

The Umeå region consists of six collaborating municipalities located in the northern county of Västerbotten, Sweden. The region has a population of 140000 citizens: 100000 live in the largest municipality, Umea and the remaining 40000 reside in more rural areas. The questionnaire was based on a thorough review of existing international measure instruments and developed to measure both structural and cognitive social capital at individual and neighbourhood levels. Representatives from the participating municipalities were actively involved in the development of the questionnaire and both officials and local politicians took part in discussions about the final design. The questionnaire covered the following content areas:

- Sociodemographic background factors

- Perceptions about living area

- Civic and political engagement

- Reciprocity and trust

- Social networks

- Social support

- Self-rated health and health-related quality of life

Individually linked register variables such as sex, age, marital status and country of birth were taken from the population register (Statistics Sweden) and added for use in this study.

\section{Measurement of Social Capital}

We wanted detailed and comprehensive measures of different forms of social capital. However, there are only a few studies that have empirically investigated the effects of different forms of social capital on health [22]. Our development of different measurements for structural and cognitive social capital was designed in accordance with sugges- tions from the literature $[4,31]$ and based on a thorough review of existing international instruments for measuring

social capital. In this paper, the analysis focuses on individual social capital. Collective social capital will be included in a separate analysis and reported elsewhere.

\section{Measurement of Structural Social Capital}

Structural social capital was measured by involvement in bonding, bridging, and linking social networks. We created indexes since these are broad concepts based on several variables. Initially, variables/items that could be theoretically linked to the concepts of bonding, bridging and linking social capital were selected and used in a confirmatory factor analysis. The factor analysis was performed using the software AMOS 17 and carried out separately for each form of structural social capital. Hence, the confirmatory factor analysis was used to examine whether our theoretically selected items also emerged as statistical clusters. For the bonding index, some variables had to be excluded due to too little variation in the item. This concerned questions such as those about "good social relations with family and friends" where more than $90 \%$ of the respondents answered "yes". Overall, this analysis indicated high levels of close relations with family and friends in the target population. The factor analysis resulted in five significantly connected items for the bonding index, three significantly connected items for the bridging index, and four significantly connected items for the linking index. Due to the large sample size, even low values of factor loadings (ie, below 0.50) became significant. However, in order to give each index equal weight, we kept the three items with the highest factor loading for each index. Hence, each index could have a total score of three. All variables where dichotomized in further analyses. Table 2 illustrates the variables included in the three indexes.

For the variables included in the bonding index, respondents were asked to answer "yes", "no" or "not applicable to me". The last option was coded as no. In the first bridging item, respondents were asked about the size of their social network, given four different options: 0-5, 6-10, 1115 , or more than 15 people, where the last option gave one score. The question about engagement in associations consisted of a list of 15 different types of associations, (such as sports, church, parents, youth, relief, or cultural groups) where involvement in at least one association was required to get one score. Concerning participation in public events the respondents were asked to answers yes or no, as well as for the variables included in the linking index. Each "yes" answer gave one score. When dichotomizing the index, one 
Table 2. Variables Included in the Bonding, Bridging and Linking Indexes Used to Assess Structural Social Capital

\begin{tabular}{|c|c|c|}
\hline Structural Social Capital & & \multicolumn{1}{c|}{ Variables Included } \\
\hline \hline BONDING & - Have good social relations with neighbours \\
Social Capital & - Have done favours for a neighbour during the last 12 months \\
& - Have received favours from a neighbour during the last 12 months \\
\hline BRIDGING & - Have a social network consisting of more than 15 people \\
Social Capital & - Have been engaged in at least one association during the last 12 months \\
& - Have participated in public events during the last 12 months \\
\hline LINKING & - Have contacted an authority or politicians in order to influence local decisions during the last 12 months \\
Social Capital & - Have participated in public meetings in order to influence local decisions during the last 12 months \\
& - Have been engaged in a political party during the last 12 month \\
\hline
\end{tabular}

to three scores were coded as having "access" to this form of social capital, while zero score was coded as having "no access".

\section{Measurement of Cognitive Social Capital}

In line with theoretical and methodological development in the field of social capital, cognitive social capital was measured using single variables for perceptions of trust, reciprocity norms, and sense of security [31]. All variables were dichotomized for the analyses. Previous studies [6, 40] have shown the importance of distinguishing between different kinds of trust, such as trust in people in general (sometimes referred to as "thin" trust), trust in people one knows (personalized or "thick" trust) and trust in formal institutions (institutionalized trust). Thus, generalized, personalized and institutionalized trusts were assessed separately.

Generalized trust was assessed by the question "do you think most people can be trusted, even those you are not personally known to?" (yes/no), where yes indicated access to generalized trust. Personalized trust was assessed by the question "Do you feel you can trust people in your neighbourhood?" with the options yes-totally, yes-partly, no-not really, no-not at all, and the first two options indicated access to personalized trust in the dichotomized measure. Institutionalized trust was assessed by the question "In general, how much do you trust the following public institutions?" followed by a list 13 public institutions (such as the social services, health care, the media and the church). Options were graded as very much, rather much, rather little, not at all, and no opinion. The first two options were combined to indicate trust in the dichotomized measure. Trust in 7-13 public institutions was classified as having access to institutional trust when the 13-item summary measure was created. Reciprocity norms was accessed by the statement; "If one help others, one can expect to get help when needed". The statement was graded on a four point scale ranging from "fully agree" to "do not agree at all". Fully agree and partly agree were combined to indicate access to reciprocity norms in the dichotomized measure. Sense of security was assessed by the question "How secure or insecure do you feel when walking alone in your neighbourhood during evenings?" The question was graded on a four point scale ranging from very secure to very insecure. The option "don't know/never out alone" was also given. Very secure and fairly secure was combined to indicate access to security in the dichotomized measure. Table 3 summarizes the variables used to assess cognitive social capital.

The partial non responses were low (less than $3 \%$ for almost all questions) and were taken into account by coding them as "no", indicating no access to that form of social capital.

\section{Measurement of Self-Rated Health}

Self-rated health was used as the outcome measure. In our study the respondents were asked to grade their general health on a five point scale from very good to very poor (How to you perceive your overall health during this last year? - Very good, fairly good, fair, fairly poor, and very poor). Those who answered that their general health was very or fairly good were considered as having good selfrated health when the measure was dichotomized.

Table 3. Variables Used to Assess Cognitive Social Capital

\begin{tabular}{|l|l|l|}
\hline \multicolumn{1}{|c|}{ Cognitive Social Capital } & & \multicolumn{1}{c|}{ Variables } \\
\hline \hline \multirow{3}{*}{ Trust } & $\bullet$ & Generalized: Trust people in general, even if not personally known \\
& - & Personalized: Trust people in the neighbourhood \\
\hline Reciprocity norms & $\bullet$ & Institutionalized: Trust at least 7 out of 13 enumerated public institutions \\
\hline Sense of security & $\bullet$ & Agree to the statement "If one help others, one can expect to get help when needed" \\
\hline
\end{tabular}




\section{Measurements of Sociodemographic Variables}

Sex (men/women) was used to indicate gender differences. Education (higher/secondary/basic) was used to categorize educational level. "Higher" education indicates university and college university education; "secondary" education indicates upper secondary, vocational or folk highschool education; and "basic" education indicates 6-9 year compulsory school education. In accordance with previous literature or [31], the following variables were considered as potential important confounders / control variables: Age (age groups 18-30, 31-64, and 65-84 years), Marital status (living with partner/living alone), Children at home (living with children below 18 years of age; yes/no), Country of birth (Sweden/other), and Level of urbanization (urban/ rural). Level of urbanization was classified into urban/rural based on participants' description of their living area. Those who described their living areas as small village or hamlet were considered to be rural while those who described their living area as a district, street, block or housing area were considered to be urban.

\section{Statistical Analyses}

The distribution of all variables by good $v s$. poor selfrated health was calculated. Crude odds ratios (OR) and 95\% confidence intervals (CI) for good self-rated health were calculated. To investigate the association between social capital and health by gender and educational level, OR and 95\% CI were calculated for good self-rated health and each form of social capital, stratified by sex and educational level, and controlled for other sociodemographic variables. OR and 95\% CI were calculated for men's and women's access to each form of social capital, controlling for all sociodemographic variables. To analyze the access to each form of social capital by educational level, OR and $95 \%$ CI were calculated for all educational groups (basic/ secondary/ higher), and controlled for all other sociodemographic variables. To analyze how access to social capital might influence differences in self-rated health by gender and educational level, OR and 95\% CI were calculated for good self-rated health for men and women as well as different educational groups. A multivariate regression model was built, stepwise controlling for a) all sociodemographic variables, b) sociodemographic variables plus access to structural social capital, c) sociodemographic variables plus access to cognitive social capital, and d) sociodemographic variables plus access to structural and cognitive social capital. All analyses were performed using SPSS version 15.0 software.

\section{RESULTS}

The response rate was approximately 60\% (8816 respondents). The non response rates were slightly higher among men $(56 \%)$ and younger people (40\%) compared to women (43\%) and older people (30\%).

Table 4 shows the distribution of variables by self-rated health, as well as crude ORs for good self-rated health for all variables. A higher proportion of the men $(71 \%)$, rated their health as good compared to women (65\%). Similarly, a higher proportion of people with a higher or secondary education reported their health as good compared to people with a basic education. Of those living in urban areas, $69 \%$ reported their health as good compared to $41 \%$ in rural areas. A slightly higher proportion of those living with partner rated their health as good compared to those living alone, as well as those living with children below 18 years of age compared to those living without children. Univariate logistic regression was used to analyze if these patterns remained significant. The results showed that men had higher odds for rating their health as good compared to women (OR 1.29). Further, a higher or a secondary degree significantly increased the odds for good self-rated health (OR 2.3 and 1.7) compared to a basic education. Living with partner significantly increased the odds of reporting good health (OR 1.39), as did living with children below 18 years of age (OR 1.42). Living in urban areas slightly increased the odds for good self-rated health (OR 1.12), while there was no significant difference in odds for good self-rated health by country of birth.

Table 4 shows that those who have access to social capital report their health as good to a greater extent than those who do not have access. This pattern concerned all forms of social capital. Univariate logistic regression showed that access to both structural and cognitive social capital significantly increased the odds for good self-rated health. The odds for good self-rated health were approximately twice as high for those with access to each form of cognitive social capital (institutional trust OR 1.82, generalized trust OR 1.98 , personalized trust OR 2.18 , reciprocity norms OR 1.86 , and sense of security OR 2.06). Access to structural social capital also increased the odds for good self-rated health, although to a lower extent; access to bridging social capital increased the odds for good self-rated health by $80 \%$, access to bonding by almost $30 \%$, while access to linking social capital just slightly increased the odds for good selfrated health (OR 1.17).

The Association between Structural and Cognitive Social Capital and Self-Rated Health by Gender and Educational Level

Table 5 illustrates the association between each form of social capital and good self-rated health, stratified by sex and educational level, and controlled for other sociodemographic variables. Access to each form of social capital, except for linking, significantly increased the odds for good self-rated health for both men and women as well as for all educational groups. Access to the cognitive forms of social capital, i.e., trust, reciprocity norms, and sense of security, was more important for good self-rated health than the structural forms of social capital, although access to bonding and bridging social capital increased the odds for good self-rated health. Thus, access to the same forms of social capital was healthenhancing for men, women, and all educational groups.

\section{Gender and Educational Level Differences in Access to Structural and Cognitive Social Capital}

Table 6 illustrates the variance in access to each form of social capital by gender and educational level after controlling for sociodemographic variables. The likelihood of having access to bonding and linking social capital was higher among men compared to women. On the other hand, women had $20 \%$ higher odds for access to bridging social capital. Concerning the cognitive forms of social 
Table 4. Distribution of Variables by Self-Rated Health, and Crude Odds Ratios (OR) with $95 \%$ Confidence Intervals (CI) for Good Self-Rated Health

\begin{tabular}{|c|c|c|c|c|}
\hline & Total $(n=8816) 100 \%$ & $\begin{array}{c}\text { Good Health }(\mathrm{n}=5982) \\
67.8 \%\end{array}$ & $\begin{array}{c}\text { Poor Health }(\mathrm{n}=\mathbf{2 8 3 4}) \\
32.2 \%\end{array}$ & $\begin{array}{l}\text { Crude OR Good Self- } \\
\text { rated Health }\end{array}$ \\
\hline \multicolumn{5}{|l|}{ Sex } \\
\hline Men & 45.1 & 70.9 & 29.1 & $1.29(1.18-1.42)$ \\
\hline \multicolumn{5}{|l|}{ Educational level } \\
\hline Basic & 24.9 & 56.0 & 44.0 & 1 \\
\hline Higher & 28.8 & 74.7 & 25.3 & $2.30(2.05-2.61)$ \\
\hline \multicolumn{5}{|l|}{ Age } \\
\hline $65-84$ & 22.8 & 57.8 & 42.2 & 1 \\
\hline $31-64$ & 60.1 & 69.5 & 30.5 & $1.66(1.50-1.85)$ \\
\hline $18-30$ & 17.2 & 74.7 & 25.3 & $2.15(1.87-2.47)$ \\
\hline \multicolumn{5}{|l|}{ Children at home } \\
\hline No & 72.8 & 65.8 & 34.2 & 1 \\
\hline Yes & 27.2 & 73.1 & 26.9 & $1.42(1.28-1.57)$ \\
\hline \multicolumn{5}{|l|}{ Level of urbanization } \\
\hline Rural living & 43.7 & 66.5 & 33.5 & 1 \\
\hline Urban living & 56.3 & 68.9 & 31.1 & $1.12(1.02-1.22)$ \\
\hline \multicolumn{5}{|l|}{ Country of Birth } \\
\hline Other & 5.7 & 67.4 & 32.6 & 1 \\
\hline Sweden & 94.3 & 67.9 & 32.1 & $1.02(0.85-1.23)$ \\
\hline \multicolumn{5}{|c|}{ STRUCTURAL SOCIAL CAPITAL } \\
\hline \multicolumn{5}{|l|}{ Bridging } \\
\hline \multicolumn{5}{|l|}{ Linking } \\
\hline No Access & 62.1 & 66.6 & 33.4 & 1 \\
\hline Access & 37.9 & 70.0 & 30.0 & $1.17(1.07-1.29)$ \\
\hline \multicolumn{5}{|c|}{ COGNITIVE SOCIAL CAPITAL } \\
\hline \multicolumn{5}{|l|}{ Institutional trust } \\
\hline No Access & 68.3 & 63.9 & 36.1 & 1 \\
\hline Access & 31.7 & 76.4 & 23.6 & $1.82(1.65-2.02)$ \\
\hline \multicolumn{5}{|c|}{ Generalized trust - agree that all people can be trusted } \\
\hline No Access & 22.6 & 55.8 & 44.2 & 1 \\
\hline Access & 77.4 & 71.4 & 28.6 & $1.98(1.79-2.19)$ \\
\hline \multicolumn{5}{|c|}{ Personalized trust - trust in neighbours } \\
\hline No Access & 7.5 & 50.8 & 49.2 & 1 \\
\hline Access & 92.5 & 69.2 & 30.8 & $2.18(1.86-2.55)$ \\
\hline \multicolumn{5}{|c|}{ Reciprocity norms - agree that helping others pays back } \\
\hline No Access & 13.9 & 55.4 & 44.6 & 1 \\
\hline Access & 86.1 & 69.9 & 30.1 & $1.86(1.65-2.11)$ \\
\hline \multicolumn{5}{|c|}{ Sense of security - level of security when walking alone at evenings } \\
\hline No Access & 17.4 & 54.1 & 45.9 & 1 \\
\hline Access & 82.6 & 70.8 & 29.2 & $2.06(1.84-2.30)$ \\
\hline
\end{tabular}


Table 5. Odds Ratios (OR) with $95 \%$ Confidence Intervals (CI) for Good-Self-Rated Health by Access to each form of Social Capital, Stratified by Sex and Educational Level

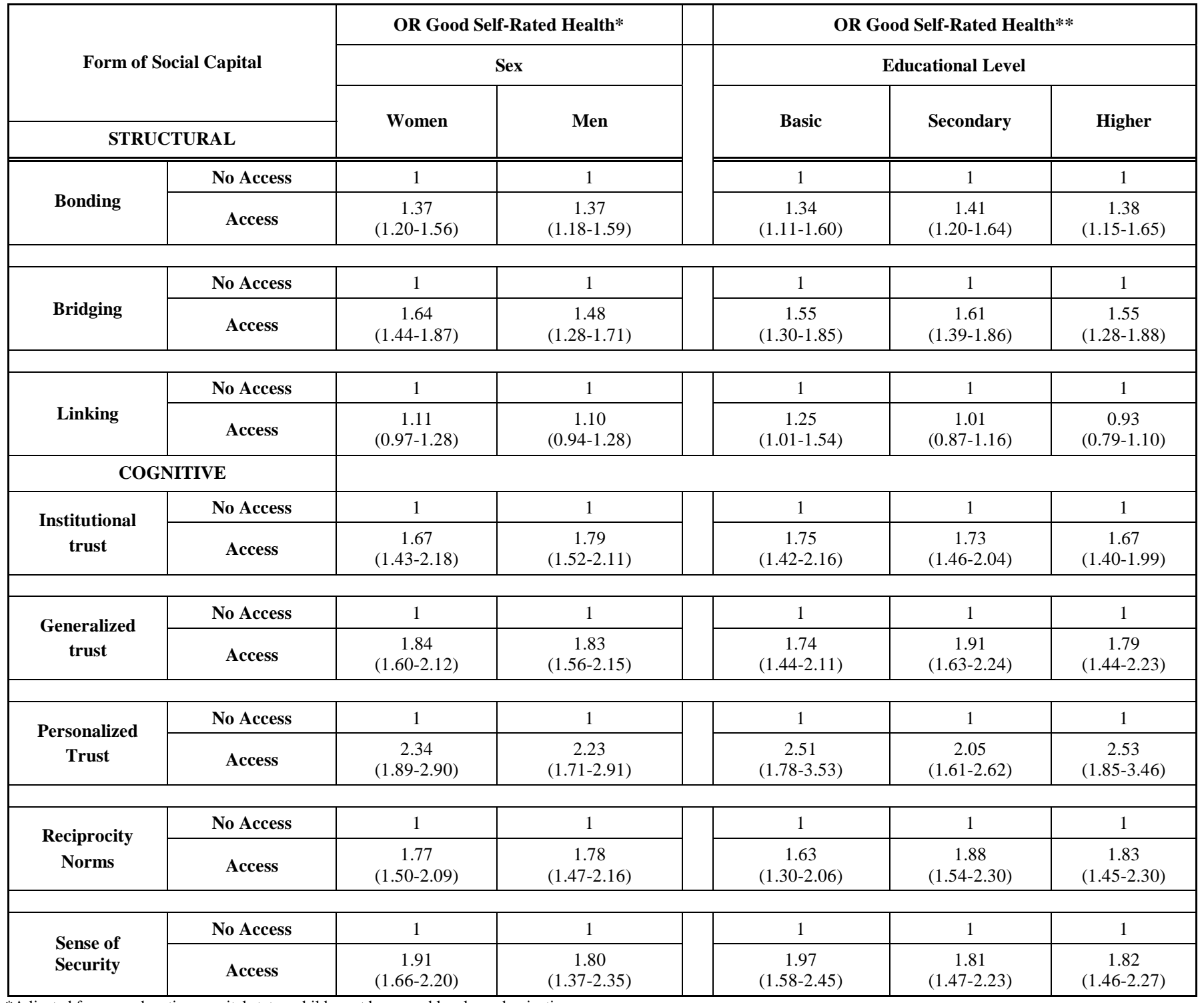

*Adjusted for age, education, marital status, children at home and level or urbanization

**Adjusted for sex, age, marital status, children at home and level of urbanization

capital, men had higher odds for access to personalized trust (OR 1.33) and slightly higher odds for access to generalized trust (OR 1.12) compared to women. Further, men had more than five times higher odds for access to a sense of security (OR 5.72) compared to women.

Table 6 shows that access to all forms of social capital was unequally distributed between different educational groups. There were significant differences between higher and basic educated individuals in access to each form of social capital. People with higher education had significantly higher odds for access to all forms of social capital compared to those with a secondary or basic education. For the structural forms of social capital, those with higher education had more than four times higher odds for access to bridging (OR 4.40), and around three times higher odds for access to linking social capital (OR 3.12) than those with basic education. This discrepancy between the educational groups was considerably smaller regarding access to bonding social capital (OR 1.38 for those with a higher education). Concerning the cognitive forms of social capital, the higher educated had three times higher odds for access to generalized trust (OR 3.04), around two times higher odds for access to institutional and personalized trust (OR 2.12 and 2.39 respectively), $70 \%$ higher odds for sense of security and $40 \%$ higher odds for access to reciprocity norms than those with a basic education.

Do differences in access to structural and cognitive social capital influence the distribution of self-rated health by gender and educational level?

A question that naturally arises is whether men's selfrated health advantage (crude OR 1.29, see Table 4) over women remains after controlling for access to social capital. Table 7 illustrates OR for good self-rated health when controlling for various variables. Men's health advantage over 
Table 6. Odds Ratios (OR) with $95 \%$ Confidence Intervals (CI) for Access to each form of Social Capital by Sociodemographic Variables

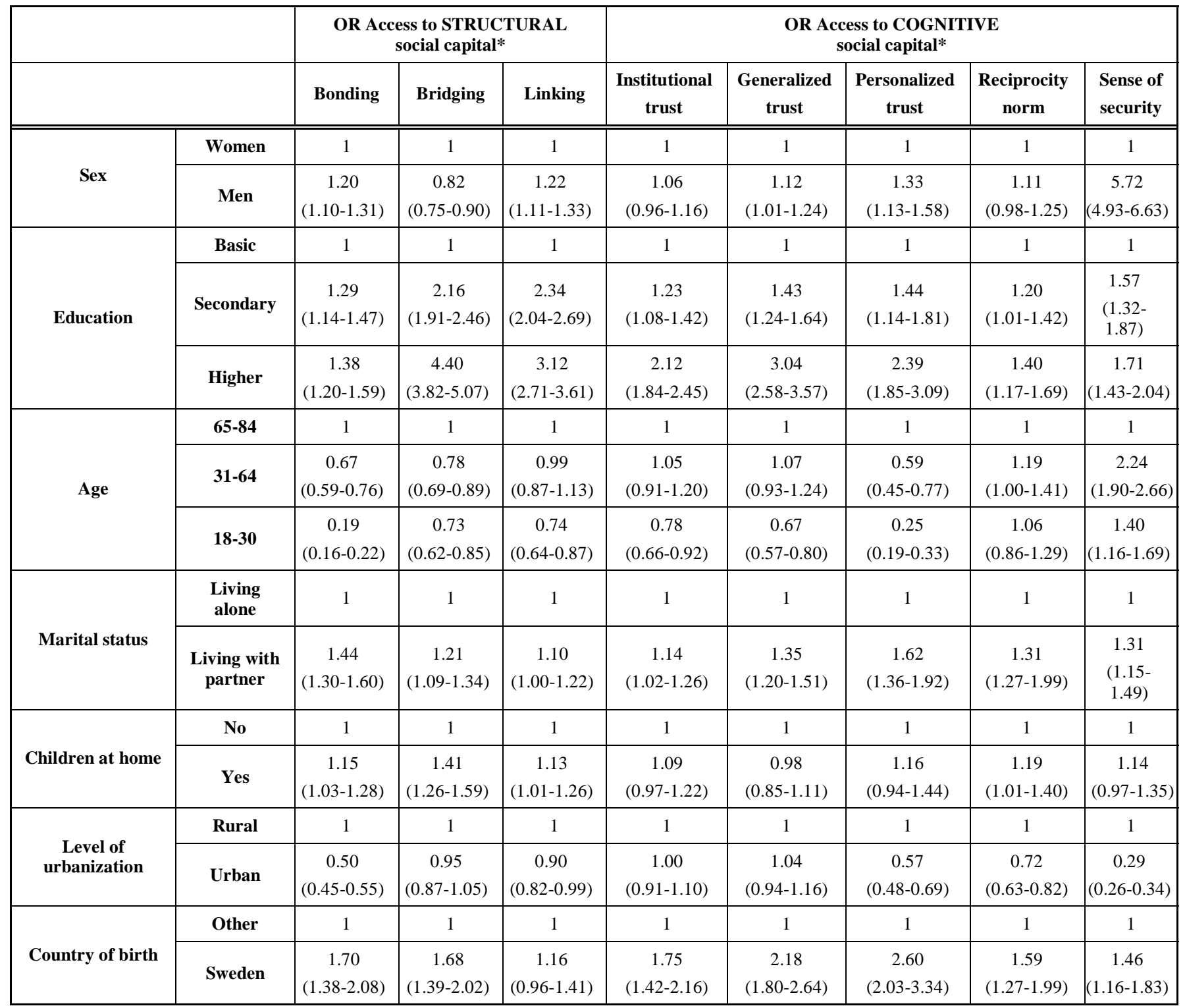

*Based on a model including all sociodemographic variables.

women increased when controlling for all sociodemographic variables (OR 1.36). When access to structural social capital was added to the model, men's health advantage remained. This can probably be explained by women's higher odds for access to bridging social capital (Table 6). However, when controlling for access to cognitive social capital, men's health advantage over women decreased (OR 1.21). This indicates that men's greater access to cognitive social capital (especially sense of security, see Table 6) can partly explain men's self-rated health advantage. No further difference in OR for good self-rated health between men and women was found when controlling for access to both structural and cognitive social capital.

Similarly, one could question if the health advantage for those with secondary and higher education (Crude OR 1.70 and 2.30 respectively) remains after controlling for access to social capital. Table 6 showed that those with a higher educational level (secondary and higher) had higher odds for access to all forms of social capital, both structural and cognitive, compared to those with a basic education. Table 7 shows how the self-rated health advantage for the high educated groups decreased when controlling for sociodemographic variables (OR 1.42 for secondary and OR 1.92 for higher education). After controlling for access to structural and cognitive social capital, the health advantage for the higher and secondary educated decreased further. When controlling for access to both structural and cognitive social capital, the odds for good self-rated health decreased even further (OR 1.25 for secondary and OR 1.50 for higher education). This indicates that the self-rated health advantage for the high and secondary educational groups can be partly explained by their higher likelihood of having access to social capital. 
Table 7. Odds Ratios (OR) with $95 \%$ Confidence Intervals (CI) for Good Self-Rated Health by Sex and Educational Level According to Four Different Models

\begin{tabular}{|c|c|c|c|c|c|}
\hline \multicolumn{2}{|c|}{} & $\begin{array}{c}\text { Model 1 } \\
\text { (Sociodemographic } \\
\text { Variables*) }\end{array}$ & $\begin{array}{c}\text { Model 2 } \\
\text { (Model 1 Plus Access to } \\
\text { Structural Social } \\
\text { Capital**) }\end{array}$ & $\begin{array}{c}\text { Model 3 } \\
\text { (Model 1 Plus Access to } \\
\text { Cognitive Social } \\
\text { Capital***) }\end{array}$ & $\begin{array}{c}\text { Model 4 } \\
\text { (Model 2 Plus Access to } \\
\text { Cognitive Social } \\
\text { Capital***) }\end{array}$ \\
\hline \multirow{3}{*}{ Sex } & Women & OR (95\% CI) & OR (95 \% CI) & OR (95 \% CI) & OR (95 \% CI) \\
\cline { 2 - 6 } & Men & $1.36(1.24-1.50)$ & $1.39(1.26-1.52)$ & $1.21(1.09-1.33)$ & 1 \\
\hline \multirow{3}{*}{ Education } & Secondary & $1.42(1.25-1.61)$ & $1.32(1.16-1.50)$ & $1.24(1.12-1.36)$ \\
\cline { 2 - 6 } & Higher & $1.92(1.68-2.21)$ & $1.69(1.46-1.95)$ & $1.62(1.40-1.87)$ & 1 \\
\cline { 2 - 6 } & & & & $1.15-1.49)$ & $1.25(1.10-1.43)$ \\
\hline
\end{tabular}

* Sex, education, age, marital status, children at home, level of urbanization, and country of birth

** Bonding, bridging and linking social capital

*** Institutional trust, generalized trust, personalized trust, reciprocity norms and sense of security

\section{DISCUSSION}

The aim of this study was to investigate the links between structural and cognitive social capital and self-rated health by gender and educational level. Further, we wanted to determine if access to social capital might explain the observed disparities in self-rated health between men, women, and different educational groups. Our results show that both structural and cognitive social capital increase the odds of good self-rated health almost equally for men and women, as well as groups with high, secondary or basic education (Table 5). While no major differences were found in the association between social capital and self-rated health by gender and educational level, large disparities were found in the odds for access to social capital, both by gender and between different educational groups (Table 6). Having a higher education significantly increases the odds for access to each form of social capital. Being a man significantly increases the odds of having access to two of three forms of structural social capital (bonding and linking) and three of five cognitive forms of social capital (generalized trust, personalized trust and sense of security). Further, the results show that the observed self-rated health advantage for men and higher education groups can be partially explained by their greater likelihood of access to social capital.

\section{The Association between Different Forms of Social Capital and Self-Rated Health}

The cognitive components of social capital used (i.e., institutional, generalized, and personalized trust, reciprocity norms, and sense of security) were in accordance with previous studies [23, 39-41]. Cognitive components increase the odds for good self-rated health more than structural components of social capital (i.e., involvement in bonding, bridging, and linking social networks). Among cognitive forms, access to personalized trust (e.g., trust in neighbors) and sense of security (e.g., feeling secure when walking alone at evening) had the greatest increase in odds for good self-rated health: all groups (OR greater than 2.0 for those with access to personalized trust and OR greater than 1.8 for those with access to sense of security), followed by generalized trust, reciprocity norms and institutional trust. Among structural forms, access to bridging social capital (i.e., large social networks, and involvement in associations and public events) increases the odds for good self-rated health approximately $50 \%$ in all groups.

Other studies have found that involvement in small informal networks (i.e., bonding social capital) is related to health [42, 43], while links between associational membership (i.e., bridging social capital) and health are less clearly demonstrated [23, 43]. The importance of associational membership for health may be influenced by contextual and historical conditions. In Sweden, associations have historically played an important role in mobilizing people for change and well-being; in other contexts, informal social networks might be more important.

\section{Social and Gender Differences in the Association Between Social Capital and Self-Rated Health}

Our results (Table 5) show a robust and similar pattern of access to both structural and cognitive social capital increasing the odds for good self-rated health irrespective of sex or educational level. No gender or social (educational) differences in the association between self-rated health and social capital were visible in our study. However, other studies have indicated that effects of social capital may differ by gender and other social aspects. Baron-Epel, Weinstein, Haviv-Mesika, Garty-Sandalon, and Green [44] found differences between Arab and Jewish Israelis with individual social capital associated with better self-rated health primarily in the Jewish majority population and to a lesser extent in the Arab minority population. Further, the access to social capital was lower in the Arab than the Jewish population. Other studies have found gender differences in the health effects of social capital. In a study from Finland, Nyqvist, Finnäs, Jakobsson, and Koskinen [41] found that in the Swedish speaking minority both men and women had access to more social capital (i.e., were more likely to attend social activities, visit family, friends and relatives, and had higher trust and sense of security) compared to the Finnish-speaking majority, which had a significantly increased likelihood of 
experiencing good self-rated and psychological health for the Swedish-speaking men but not the Swedish-speaking women. In their study from Tasmania, Australia, Kavanagh, Bentley, Turrell, Broom, and Subramanian [45] found that some forms of social capital at the area level, i.e., neighborhood safety and political participation, reduced the risk of poor self-rated health for women but not men. Similarly, Stafford, Cummins, Macintyre, Ellaway, and Marmot [46] investigated gender differences in the association between health and neighborhood environment in the UK and found that some forms of neighborhood social capital (social cohesion), i.e., trust and integration into wider society, had greater influence on women's than men's self-rated health. Living in a neighborhood with low levels of trust and integration significantly increased the odds for less than good self-rated health for women but not men. Thus, the findings of gender differences between social capital and health are inconsistent. This fact might be due to level of analyses. The above studies indicate that area level (i.e., collective) social capital might be more important for women's than men's health, while individual social capital might be equally important for men and women. However, the effect of social capital on health might also differ by contextual conditions and this could explain why gender differences in the effects of individual social capital were found in a Finnish study [41] but not in our study. Comparing different groups of women and men (such as Finnish/Swedish) in the same population might also lead to different results compared to the analysis of men versus women as we did.

\section{Negative Health Effects of Social Capital}

We found no indication that access to some forms social capital might be bad for health, although this has been found in other studies. In their study about sexual health and social capital in a South-African mining community, Campbell, Williams, and Gilgen [47] showed that associational membership could be both positive and negative for sexual health. Involvement in sport clubs was associated with positive sexual health for both men and women, while involvement in so called "saving clubs" (stokvels) was associated with negative sexual health for both men and women. Mitchell and LaGory [48] investigated the link between individual bonding and bridging social capital and mental distress in a deprived southern US city neighborhood and found that bonding social capital is associated with mental distress. Thus, strong ties may also be burdensome for the main providers who are often women. Kawachi and Berkman [49] found that the stress-related negative consequences of social networks have greater influence on the women's psychological health than the positive effects of support. One limitation in our study is the treatment of men and women as homogenous groups, which might obscure that the effect of social capital may differ between different subgroups among men and women. In our study, those living with children less than 18 years of age had significantly higher odds for access to bridging social capital after controlling for all the included sociodemographic variables compared to those living without children (Table 6). Further, this group had approximately $40 \%$ higher odds for good self-rated health (Table 4). However, after controlling for the sociodemographic variables, this health advantage almost disappeared (data not shown). Thus, access to bridging social capital may not necessarily be health enhancing. Further studies are needed to investigate the effects of social capital for different subgroups of men and women while considering factors such as family structure and age.

\section{Social and Gender Inequality in Access to Social Capital}

Our results revealed great disparities in access to social capital between groups: the higher educated are more likely to have access to all forms of social capital compared to people with basic education; men are more likely of having access to some forms of social capital than women. Several studies have indicated that social capital is not an equal resource in a society but differs between age, ethnic and social groups and between men and women. In a survey of households in Adelaide, Australia, Ziersch [43] found that those with greater resources and higher education also had greater access to social capital. In their qualitative studies, Campbell, Wood, and Kelly [42] found large differences in how men and women create their social networks and in the support they gain from them. Moss [50] discussed how men and women have unequal access to social capital due to gender constructions, culture and norms. In their study on urban-rural networks during the 1997-1999 Indonesian economic crisis, Silvey and Elmhirst found that women's involvement in social networks had protective effects during the time of crisis [51]. Since women's social capital was highly affected by gender expectations of caring for other family members, their social capital primarily consisted of bonding social networks. This excluded them from more powerful social networks and opportunities. Conversely, we found that women in our study were less likely of having access to bonding social capital (remember that we measured bonding as good relations with neighbours and not as good and close relations with family, relatives and friends). In accordance with Putnam [6], we instead found that women had higher access to bridging social capital (i.e., involvement in associations, public events and big social networks) than men. This fact may be a result of existing gender relations, such as higher expectations that women will be involved in civil society and children's activities.

Sociological views (such as Bourdieu's [9]) on social capital add important power perspectives by stating that membership in groups, i.e., possession of social capital, is not something naturally given but a product of collective or individual investment strategies. The dominant groups in a society are thus capable of building powerful networks, excluding those with fewer resources to invest. Accordingly, one could assume that the resources following with higher education (i.e., human and economic capital) also facilitates the access to social capital, which could explain why groups with high education have higher odds for access to all forms of social capital. Similarly, men's higher odds of access to social capital compared to women could be explained by the existence of male-dominated gender structures. In our study, the most striking difference between men and women concerned a sense of security: men were more than five times more likely to feel secure when walking alone in the neighborhood at evening. This finding indicates a serious gender inequality in sense of security that is one aspect of access to social capital that probably influenced the observed health inequality between men and women in our study setting. 


\section{Limitations}

Some limitations with this study need to be considered. One main limitation is the cross-sectional nature, implying that reverse causality cannot be ruled out (i.e., that good selfrated health leads to access to social capital). Longitudinal studies are needed to further elucidate the causal pathways between social capital and health. In our survey, the respondents were asked to voluntarily provide their personal identity number to allow for future follow-up studies and 3500 of the respondents $(40 \%)$ did so. Future studies will allow us to follow these people over time to analyze changes in self-rated health and access to social capital. We did not have any questions regarding health behaviour or risk factors in our survey and this can be seen as a limitation. Health behaviours such as smoking and physical activity can probably influence both self-rated health and access to social capital. Future follow up studies will allow us to connect our survey data to other health registers. Finally, the higher non response rates for men might bias the results if the male respondents are healthier than those men who did not respond. However, our finding that Swedish men are more likely to rate their health as good compared to Swedish women is consistent with previous research [34] and this makes selection bias less likely.

\section{CONCLUSIONS}

This study supports the idea that access to both structural and cognitive social capital increases the odds for good selfrated health. The positive association between access to social capital and good self-rated health was equal for both men and women as well as for all educational groups. However, the likelihood for access to social capital was unequal distributed by gender and educational level. The secondary and higher education groups were more likely to have access to all forms of structural and cognitive social capital compared to the basic education group. Similarly, men were more likely to have access to some forms of structural and cognitive social capital compared to women. The health advantage for the secondary and higher education groups, as well as men's health advantage over women, partly disappeared when controlling for access to social capital. These findings indicate that access to social capital can explain to some extent the observed health inequality between men and women and different educational groups. These results have implications for public health interventions. Strengthening social capital where it is lacking might be one way of lessening health inequality. However, when trying to strengthen social capital for health promotion purposes one must also consider the structural and political conditions that create the unequal opportunities to access social capital.

\section{ACKNOWLEDGEMENTS}

This work was undertaken within the Centre for Global Health at Umeå University, with support from FAS, the Swedish Council for Working Life and Social Research (Grant no. 2006-1512). We would like to express our thanks to Hans Stenlund for consultation on data analyses and statistical issues and to Ed Fottrell and Lennart Nyström for consultation on data presentation.

\section{ETHICS}

All respondents were informed about the study and data handling in a cover letter enclosed with the questionnaire. Answering the questionnaire was regarded as consent to join the study. The study was approved by the regional ethics committee in Umeå (Dnr 04-172M §11/05).

\section{REFERENCES}

[1] Schuller T, Baron S, Field, J. Social capital: a review and critique. In: Baron S, Field J, Schuller T, Eds. Social capital: Critical perspectives. New York: Oxford University Press 2000; pp. 1-38.

[2] Portes A. Social capital: Its origins and applications in modern sociology. Annu Rev Sociol 1998; 24: 1-24.

[3] Kawachi I, Subramanian SV, Kim D. Social capital and health: A decade of progress and beyond. In: Kawachi I, Subramanian SV, Kim D, Eds. Social capital and health. New York: Springer 2008; pp. 1-26.

[4] Rostila M. Healthy bridges. Studies of social capital, welfare, and health. PhD [dissertation]. Stockholm: Stockholm University 2008.

[5] Putnam RD. Making democracy work: Civic traditions in modern Italy. Princeton, New Jersey: Princeton University Press 1993.

[6] Putnam RD. Bowling alone: The collapse and revival of American community. New York: Simon \& Schuster 2000.

[7] Szreter S, Woolcock M. Health by association? Social capital, social theory, and the political economy of public health. Int $\mathbf{J}$ Epidemiol 2004; 33: 650-67.

[8] Kawachi I, Berkman L. Social cohesion, social capital, and health. In: Berkman LF, Kawachi I, Eds. Social epidemiology. New York: Oxford University Press 2000; pp. 174-90.

[9] Bourdieu P. The forms of capital. In: Richardson JG, Ed. Handbook of theory and research for the sociology of education. Westport, Connecticut: Greenwood Press 1986; pp. 241-58.

[10] Coleman JS. Social capital in the creation of human capital. Am J Sociol 1988; 94(Suppl): 95-120.

[11] Marmot, MG. Status syndrome. A challenge to medicine. J Amer Med Assoc 2006; 295: 1304-7.

[12] Kawachi I, Kennedy BP, Lochner K, Prothrow-Stith D. Social capital, income inequality, and mortality. Am J Public Health 1997; 87: 1491-8.

[13] Wilkinson RG, Kawachi I, Kennedy BP. Mortality, the social environment, crime and violence. Sociol Health Ill 1998; 20: 57897.

[14] Kennedy BP, Kawachi I, Brainerd E. The role of social capital in the Russian mortality crisis. World Dev 1998; 26: 2029-43.

[15] Sundquist J, Johansson S-E, Yang M, Sundquist K. Low linking social capital as a predictor of coronary heart disease in Sweden: A cohort study of 2.8 million people. Soc Sci Med 2006; 62: 954-63.

[16] Kim D, Subramanian SV, Gortmaker SL, Kawachi I. US State-and County-level Social capital in relation to obesity and physical inactivity: A multilevel, multivariable analysis. Soc Sci Med 2006; 63: 1045-59.

[17] Kawachi I, Kennedy BP, Glass, R. Social capital and self-rated health: A contextual analysis. Am J Public Health 1999; 89: 1187 93.

[18] Rose, R. How much does social capital add to individual health? A survey study of Russians. Soc Sci Med 2000; 51: 1421-35.

[19] Hyyppä MT, Mäki J. Individual-level relationships between social capital and self-rated health in a bilingual community. Prev Med 2001; 32: 148-55.

[20] Kim D, Subramanian SV, Kawachi I. Bonding versus bridging social capital and their associations with self-rated health: a multilevel analysis of 40 U.S. communities. J Epidemiol Commun Health 2006; 60: 116-22.

[21] Mohseni M, Lindström M. Social capital, trust in the health-care system and self-rated health: The role of access to health care in a population-based Study. Soc Sci Med 2007; 64: 1373-83.

[22] Engström K, Mattsson F, Järleborg A, Hallqvist J. Contextual social capital as a risk factor for poor self-rated health: A multilevel analysis. Soc Sci Med 2008; 66: 2268-80.

[23] Kim D, Subramanian SV, Kawachi I. Social capital and physical health. A systematic review of the literature. In: Kawachi I, Subramanian SV, Kim D, Eds. Social capital and health. New York: Springer 2008; pp.139-90. 
[24] Björner JB, Sondergaard Kristensen T, Orth-Gomer K, Tibblin G, Sullivan M, Westerholm P. Self-rated health; A useful concept in research, prevention and clinical medicine. Stockholm; FRN, Swedish Council for Planning and Coordination of Research 1996.

[25] Martikainen P, Aromaa A, Heliövaara M, et al. Reliability of perceived health by sex and age. Soc Sci Med 1999; 48: 1117-22.

[26] Idler EL, Benyamini Y. Self-Rated health and mortality: A review of twenty-seven community studies. J Health Soc Behav 1997; 38: 21-37.

[27] Benyamini Y, Idler EL. Community studies reporting association between self-rated health and mortality: Additional studies, 19951998. Res Aging 1999; 21: 392-401.

[28] Emmelin M. Self-rated health in public health evaluation. PhD [dissertation]. Umeå: Umeå University 2004.

[29] Lynch J, Due E, Muntaner C, Davey Smith G. Social capital - Is it a good investment strategy for public health? J Epidemiol Commun Health 2000; 54: 404-8.

[30] Muntaner C, Lynch J. Social capital, class gender and race conflict, and population health: An essay review of bowling alone's implication for social epidemiology. Int J Epidemiol 2002; 31: 2617.

[31] Harpham T, Grant E, Thomas E. Measuring social capital within health surveys: Key issues. Health Policy Plann 2002; 17: 106-11.

[32] Wakefield SEL, Poland B. Family, friend or foe? Critical reflections on the relevance and role of social capital in health promotion and community development. Soc Sci Med 2005; 60: 2819-32.

[33] Smirthwaite G. (O) jämställdhet i hälsa och vård - en genusmedicinsk kunskapsöversikt. [(In) equality in health and health care - a gender medical review]. Stockholm: Swedish Association of Local Authorities and Regions 2007.

[34] Swedish National Institute of Public Health. Resultat från nationella folkhälsoenkäten 2007 [Results from the national public health survey 2007][Accessed 2010 March 5]. Available from: http://www.fhi.se/Documents/Statistik-uppfoljning/ Folkhalsoenkaten/Resultat-arkiv/Rapporter/Nat-Reg-2007.pdf

[35] Boström G, Nykvist K. Levnadsvanor och hälsa - de första resultaten från den nationella folkhälsoenkäten Hälsa på lika villkor. [Ways of living and health - the first results from the national public health survey, health on equal terms]. Östersund: Swedish National Institute of Public Health 2004.

[36] Krishna A, Shrader E. Cross-cultural measures of social capital: A tool and results from India and Panama. Washington DC: The World Bank; 2000. Social Capital Initiative, Working paper No. 21.
[37] Gittell R, Vidal A. Community organizing. Building social capital as a development strategy. Thousand Oaks, California: Sage Publications 1998.

[38] Ferlander S. The importance of different forms of social capital for health. Acta Sociol 2007; 50: 115-28.

[39] Yip W, Subramanian SV, Mitchell AD, Lee, DTS, Wang J, Kawachi I. Does social capital enhance health and well-being? Evidence from rural China. Soc Sci Med 2007; 64: 35-49.

[40] Harpham T, Grant E, Rodriguez C. Mental health and social capital in Cali, Colombia. Soc Sci Med 2004; 58: 2267-77.

[41] Nyqvist F, Finnäs F, Jakobsson G, Koskinen S. The effect of social capital on health: The case of two language groups in Finland. Health Place 2008; 14: 347-60.

[42] Campbell C, Wood R, Kelly M. Social capital and health. London: Health Education Authority 1999.

[43] Ziersch AM. Health implications of access to social capital: Findings from an Australian study. Soc Sci Med 2005; 61: 211931.

[44] Baron-Epel O, Weinstein R, Haviv-Mesika A, Garty-Sandalon N, Green MS. Individual-level analysis of social capital and health: A comparison of Arab and Jewish Israelis. Soc Sci Med 2008; 66: 900-10.

[45] Kavanagh AM, Bentley R, Turrell G, Broom DH, Subramanian SV. Does gender modify associations between self rated health and the social and economic characteristics of local environments? Epidemiol Commun Health 2006; 60: 490-95.

[46] Stafford M, Cummins S, Macintyre S, Ellaway A, Marmot M. Gender differences in the associations between health and neighbourhood environment. Soc Sci Med 2005; 60: 1681-92.

[47] Campbell C, Williams B, Gilgen D. Is social capital a useful conceptual tool for exploring community level influences on HIV infection? An exploratory case study from South Africa. Aids Care 2002; 14: 41-54.

[48] Mitchell CU, LaGory M. Social capital and mental distress in an impoverished community. City Commun 2002; 1: 199-222.

[49] Kawachi I, Berkman LF. Social ties and mental health. J Urban Health: B New York Acad Med 2001; 78: 458-67.

[50] Moss NE. Gender equity and socioeconomic inequality: A framework for the patterning of women's health. Soc Sci Med 2002; 54: 649-61.

[51] Silvey R, Elmhirst R. Engendering social capital: Women workers and rural-urban networks in Indonesia's crisis. World Dev 2003; 31: 865-79.

(C) Eriksson et al.; Licensee Bentham Open .

This is an open access article licensed under the terms of the Creative Commons Attribution Non-Commercial License (http://creativecommons.org/licenses/bync/3.0/), which permits unrestricted, non-commercial use, distribution and reproduction in any medium, provided the work is properly cited. 